02

\title{
Оптические и фотоэлектрические свойства тонких пленок GaS и гетероструктуры GaS/InSe
}

\author{
(C) А.Г. Гусейнов ${ }^{1}$, В.М. Салманов ${ }^{1}$, Р.М. Мамедов ${ }^{1}$, А.А. Салманова ${ }^{2}$, Ф.М. Ахмедова ${ }^{1}$ \\ ${ }^{1}$ Бакинский государственный университет, \\ AZ1148 Баку, Азербайджан \\ ${ }^{2}$ Азербайджанский государственный университет нефти и промышленности, \\ AZ1010 Баку, Азербайджан \\ e-mail: vagif_salmanov@yahoo.com
}

Поступила в редакцию 16.07.2018 г.

В окончательной редакции 08.11.2018г.

Принята к публикации 28.12.2018 г.

Экспериментально получены тонкие пленки GaS методом SILAR, проанализирована их структура и исследованы оптические и фотоэлектрические свойства. При помощи дифракционного анализа рентгеновских лучей (XRD), атомного силового микроскопа (AFM), спектроскопии дисперсной энергии рентгеновских лучей (EDAX) и сканирующего электронного микроскопа (SEM) исследованы внутреннее строение и структура полученных образцов. Из спектра поглощения определена ширина запрещенной зоны $\mathrm{GaS}$. Ha основе кристаллов $\mathrm{GaS}$ и тонких пленок InSe созданы гетеропереходы $p-\mathrm{GaS} / n$-InSe. Экспериментально исследованы вольт-амперные, оптические, фотоэлектрические и люминесцентные характеристики гетеропереходов $p$ $\mathrm{GaS} / n$-InSe.

DOI: $10.21883 / \mathrm{OS} .2019 .05 .47649 .205-18$

\section{Введение}

Соединение $\mathrm{GaS}$ относится к широкозонным полупроводникам и кристаллизуется в гексагональной сингонии с пространственной группой $P 63 / \mathrm{mm}$ с параметрами ячейки $a=0.3578 \mathrm{~nm}, c=1.547 \mathrm{~nm}[1,2]$. В направлении оси $c$ между взаимосвязанными атомными плоскостями галлия существует слабая связь ван-дер-ваальсова характера, которая способствует легкому механическому скалыванию кристалла в направлении, перпендикулярном оси $c$. Следовательно имеется возможность получения 2D-структуры на основе $\mathrm{GaS}$ либо методом интеркалирования, либо отслоением кристаллического слитка механическим способом.

Ширина запрещенной зоны $\mathrm{GaS}$ при $295 \mathrm{~K}$ составляет $2.53-3 \mathrm{eV}$, а край полосы фундаментального оптического поглощения формируется непрямыми переходами [3]. Теоретические расчеты энергетической зонной структуры зоны проводимости $\mathrm{GaS}$ показали, что в точке „Г“ в центре зоны Бриллюэна расположены три минимума с разной кривизной. Минимумы удалены от дна зоны проводимости на $8 \mathrm{meV}$ (два минимума) и на $22 \mathrm{meV}$ (один минимум) [4]. Следовательно, неравновесные электроны из этих подзон могут осуществлять излучательные рекомбинации с энергиями 2.53, 2.61 и $2.75 \mathrm{eV}$. Taким образом, кристаллы $\mathrm{GaS}$ являются перспективным материалом в качестве рабочего элемента светодиодов, излучающих свет от синего до зеленого. В настоящей работе приводятся экспериментальные результаты получения тонких пленок $\mathrm{GaS}$ и гетеропереходов $\mathrm{GaS} / \mathrm{InSe}$, анализ их структуры и исследование их оптических и фотоэлектрических свойств.

\section{Техника эксперимента}

Монокристаллы сульфида галлия были выращены методом Бриджмена в горизонтальном варианте. Поверхность кристалла получалась зеркально гладкой в направлении, перпендикулярном кристаллической оси . В этом направлении кристаллы легко скалывались на пластинки с плоскопараллельными поверхностями. Тонкие пленки $\mathrm{GaS}$ на стеклянной подложке были получены методом ионной адсорбции и реакции (метод SILAR) из раствора, содержащего сульфат галлия $\mathrm{Ga}_{2}\left(\mathrm{SO}_{4}\right)_{3}$ и тиосульфат натрия $\left(\mathrm{Na}_{2} \mathrm{~S}_{2} \mathrm{O}_{3} \times 5 \mathrm{H}_{2} \mathrm{O}\right)$ с добавлением винной кислоты $\left(\mathrm{C}_{4} \mathrm{H}_{6} \mathrm{O}_{6}\right)$. Для получения гетероструктуры $p-\mathrm{GaS}-n$-InSe на свежесколотой поверхности $\mathrm{GaS}$ методом взрывного испарения были нанесены пленки из $n$-InSe толщиной $\sim 80 \mathrm{~nm}$. Пленки $n$-InSe имели поликристаллическую структуру.

В качестве источников излучения использовались галогенная лампа накаливания и импульсный $\mathrm{Nd}$ : YAG-лазер со встроенными генераторами 2-й и 3-й гармоник, предназначенный для генерации излучения с длиной волны 1064, 532 и $355 \mathrm{~nm}$. Длительность лазерного импульса составляла $12 \mathrm{~ns}$ с максимальной мощностью $\sim 10 \mathrm{MW} / \mathrm{cm}^{2}$. Интенсивность излучения изменялась при помощи калиброванных нейтральных световых фильтров.

Спектры поглощения исследованных образцов были измерены с помощью спектрофотометра UV-VIS Lambda 25 (Perkin Elmer). При исследовании спектров фотолюминесценции был использован автоматизированный монохроматор с двойной дисперсией М833 (спектральное разрешение $\sim 0.024 \mathrm{~nm}$ на длине волны 
$a$
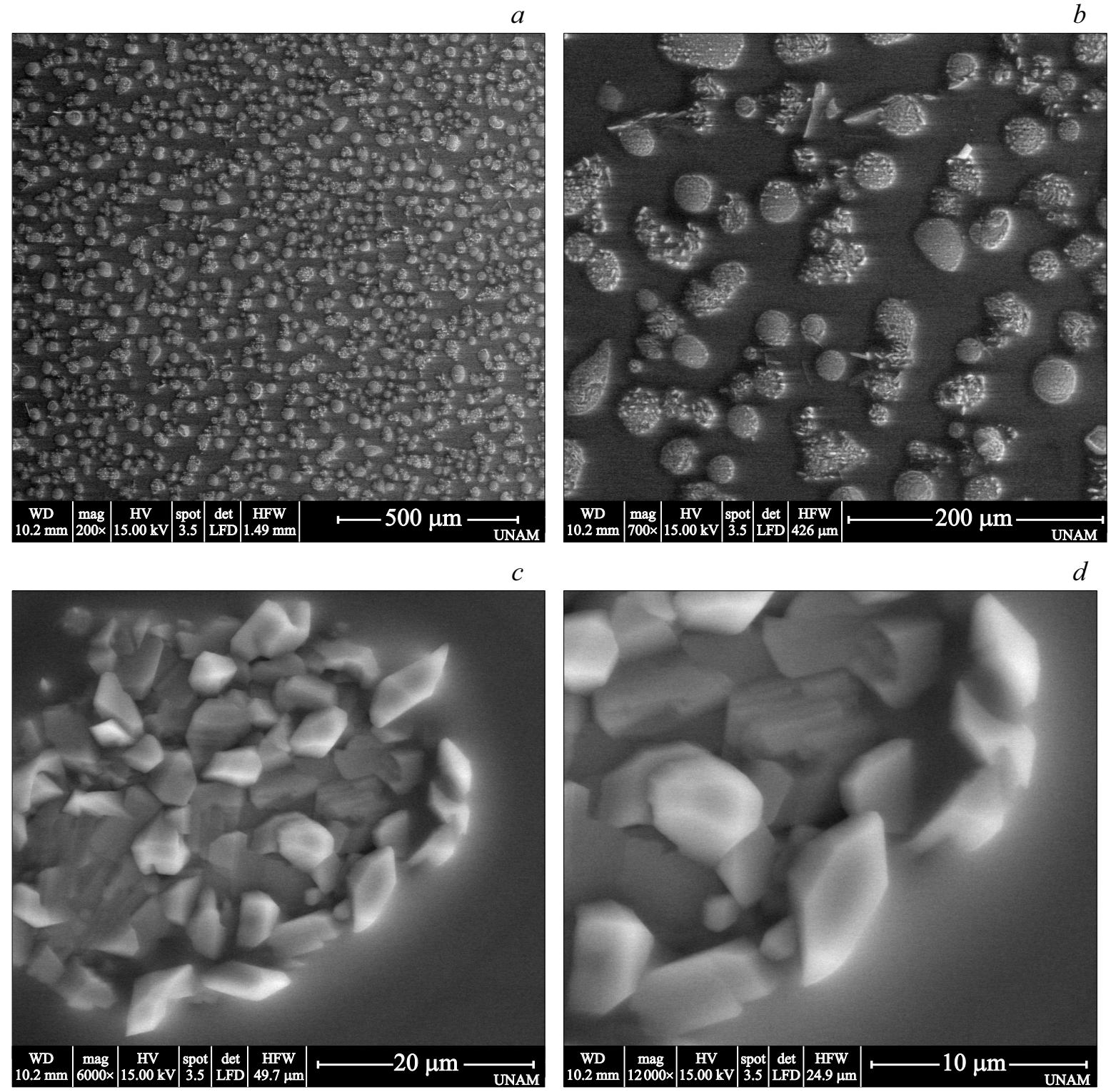

Рис. 1. SEM-изображение тонких пленок $\mathrm{GaS}$ на стеклянной подложке при различных увеличениях: $a-200 \times, b-700 \times, c-$ $6000 \times, d-12000 \times$.

$600 \mathrm{~nm})$ с компьютерным управлением и детектором, регистрирующим излучение в диапазоне длин волн $350-2000 \mathrm{~nm}$. Регистрация импульсов фототока производилась по методике, позволяющей записывать на экране запоминающего осциллографа (Tektronix TDS2012C) одиночные наносекундные импульсы.

При помощи дифракционного анализа рентгеновских лучей (XRD), сканирующего электронного микроскопа (SEM) и атомного силового микроскопа (AFM) исследованы внутреннее строение и структура полученных образцов.

На рис. 1 представлены изображения тонких пленок $\mathrm{GaS}$, полученные с помощью электронного микроскопа (SEM). Видно, что частицы $\mathrm{GaS}$ неоднородно распределены на поверхности.
На рис. 2, $а$ показано изображение AFM тонких пленок GaS. Как видно из рисунка, пленка не гомогенно распределена на стеклянной подложке. На рис. 2, $b$ приведен спектр XRD тонких пленок GaS. Спектр задается для углов $2 \theta$, в интервале от $10^{\circ}$ до $70^{\circ}$. Рентгеноструктурным анализом установлено, что выращенные тонкие пленки $\mathrm{GaS}$ имеют кристаллическую структуру и обладают гексагональной сингонией.

Оптический спектр поглощения тонких пленок $\mathrm{GaS}$ приведен на рис. 3, a. Как видно из рисунка, спектр охватывает диапазон длин волн в интервале 400-1100 nm. Начиная с $600 \mathrm{~nm}$, в сторону коротких длин волн наблюдается резкое увеличение коэффициента поглощения. Из зависимости $\alpha^{1 / 2}=f(h v)$ (рис. $\left.3, b\right)$ определена ширина запрещенной зоны в $\mathrm{GaS}$, которая оказалась 

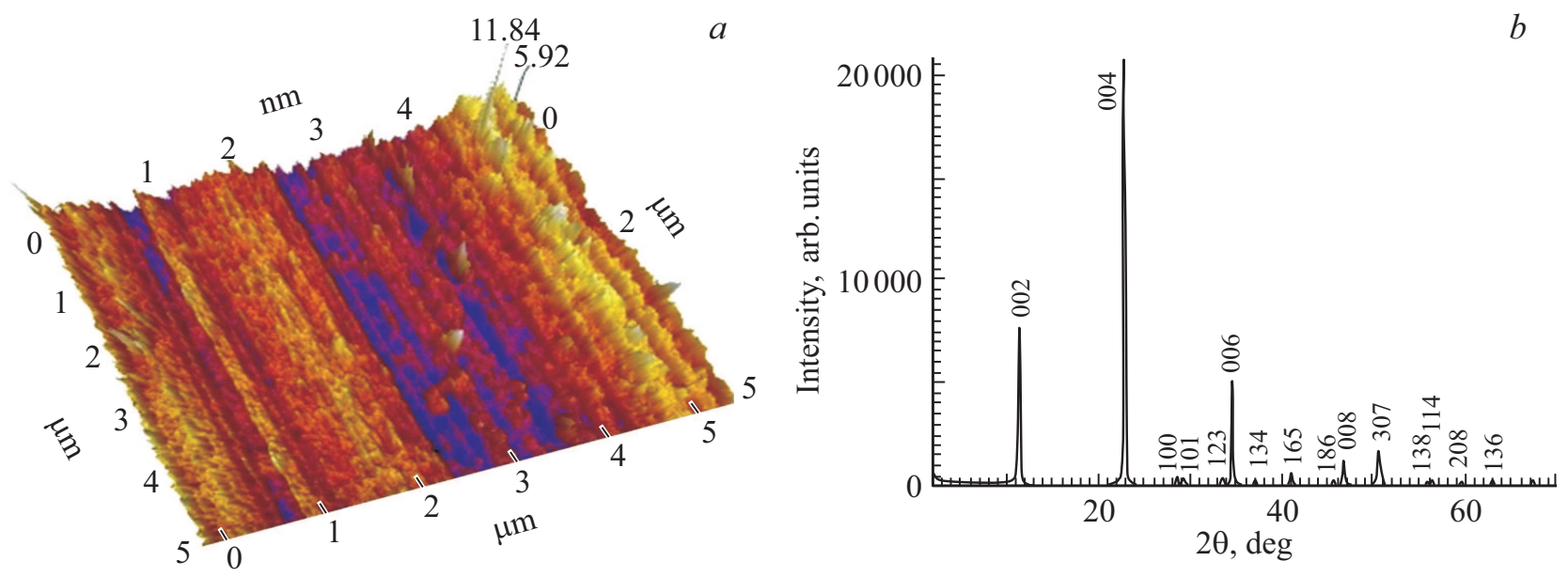

Рис. 2. $a$ - изображение AFM тонких пленок $\mathrm{GaS}, b$ - спектр XRD тонких пленок $\mathrm{GaS}$.
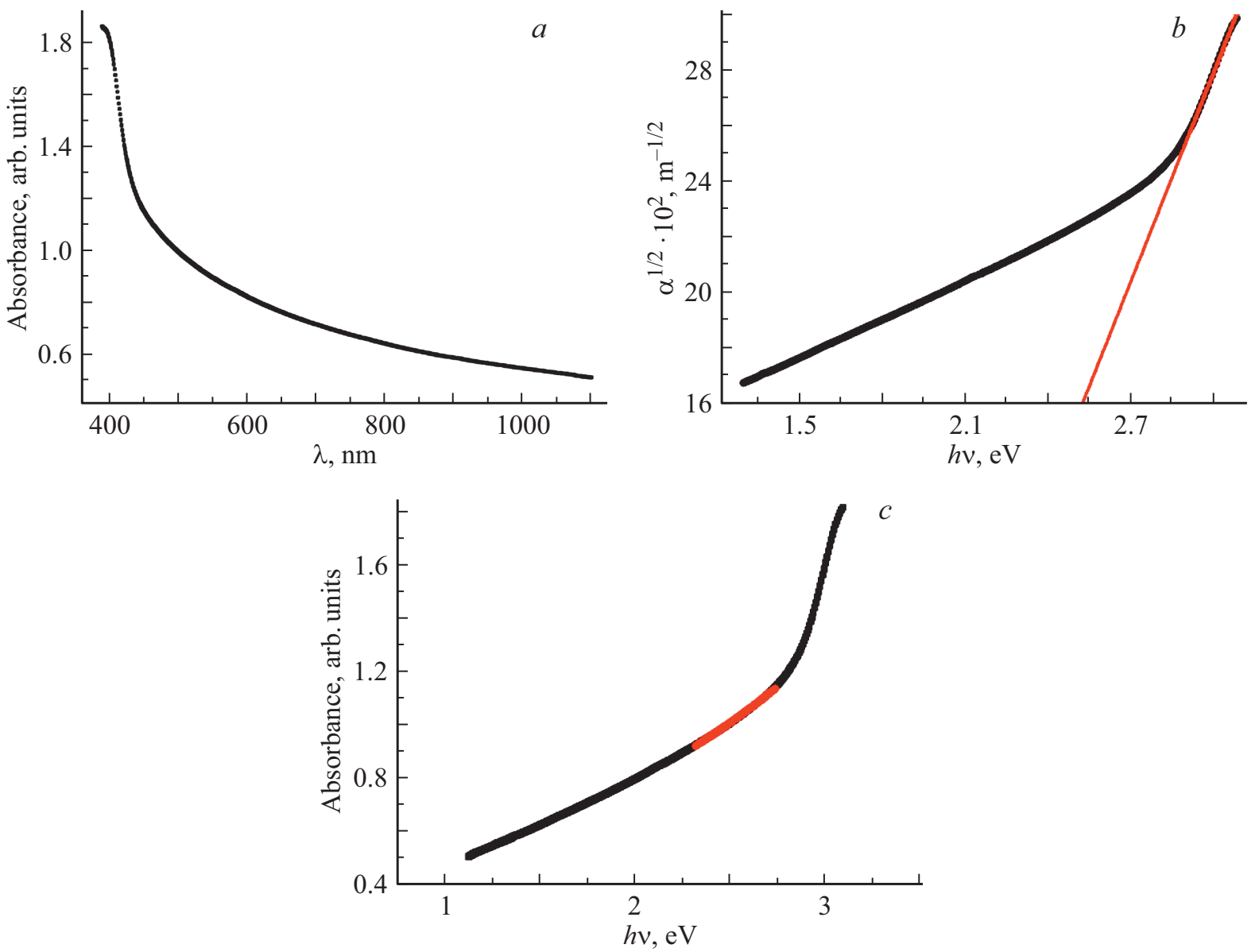

Рис. 3. $a-$ спектр поглощения тонких пленок $\mathrm{GaS}$ на стеклянной подложке, $b-$ зависимость для тонких пленок $\mathrm{GaS}, c-$ длинноволновый край спектра поглощения тонких пленок $\mathrm{GaS}$.

равной $E_{g}=2.53 \mathrm{eV}$. Эта величина находится в удовлетворительном согласии с результатами работ [5,6] для непрямого перехода в $\mathrm{GaS}$.

Из рис. 3, с видно, что начиная с энергии $\sim 1.2 \mathrm{eV}$ длинноволновой край спектра поглощения тонких пленок $\mathrm{GaS}$ изменяется экспоненциально с увеличением энергии по правилу Урбаха [7,8]:

$$
\alpha=\alpha_{0} \exp \left(\frac{h v-E_{0}}{E_{u}}\right),
$$

где $E_{u}$ - энергия Урбаха, $E_{0}$ - некоторая характеристическая энергия. Энергия Урбаха $\sim 1.93 \mathrm{eV}$, определенная 

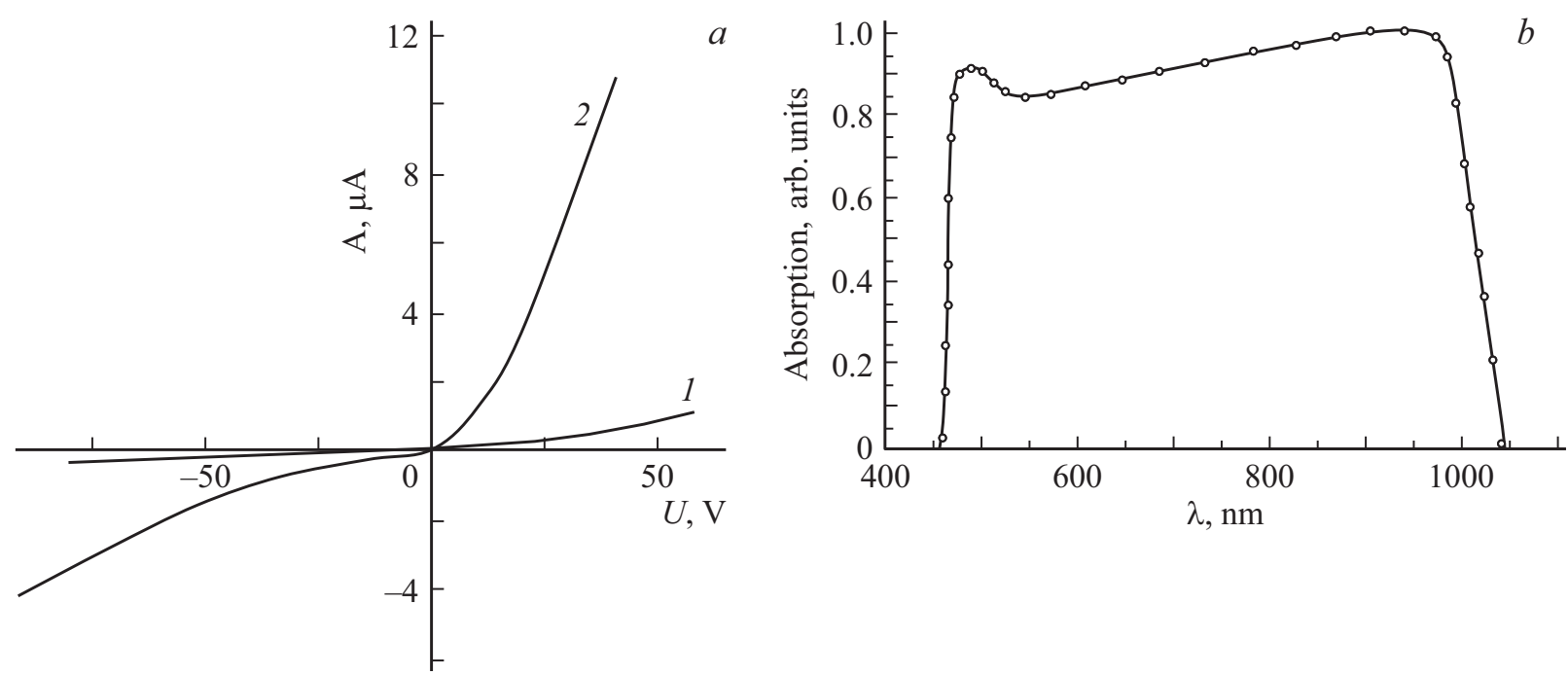

Рис. 4. $a-\mathrm{BAX}$ гетероперехода $p-\mathrm{GaS} / n-\mathrm{InSe}$, предварительно облученного лазерным излучением, в темноте (1) и при освещении (2) светом лампы накаливания $200 \mathrm{lk} ; b$ - спектральная зависимость фототока гетероструктуры $p$-GaS $/ n$-InSe.

из экспериментальных измерений, удовлетворительно согласуется с расчетными данными.

Следует отметить, что фотоэлектрические свойства кристаллов $\mathrm{GaS}$ были подробно исследованы в работе [9]. Аналогичные исследования структурных, оптических и фотоэлектрических свойств ранее нами были проведены в тонких пленках InSe [10]. На основе этих исследований, проведенных в $\mathrm{GaS}$ и InSe, были сформированы гетероструктуры $p-\mathrm{GaS} / n$-InSe.

Полученная нами гетероструктура $p$-GaS $/ n$-InSe обладает диодной характеристикой, коэффициент выпрямления при $2 \mathrm{~V}$ составляет $\sim 2 \cdot 10^{2}$ (рис. 4, $a$ ). Как показывают экспериментальные результаты, лазерное излучение значительно влияет на вольт-амперные характеристики (BАХ) исследованных образцов. При высоких уровнях оптического возбуждения $\left(W \approx 6 \mathrm{MW} / \mathrm{cm}^{2}\right)$ фоточувствительность гетероструктуры возрастает на два порядка.

На рис. 4, $b$ представлен спектр поглощения гетероструктуры $p$-GaS $/ n$-InSe. Как видно из рисунка, оптический спектр гетероструктуры $p$-GaS $/ n$-InSe охватывает широкую область длин волн от 400 до $1100 \mathrm{~nm}$. При этом длинноволновая область спектра относится к тонкой пленке $n$-InSe, тогда как коротковолновая сторона спектра определяется поглощением в кристалле $p$-GaS.

Фотопроводимость гетероструктуры $p$-GaS- $n$-InSe измерялась в режиме постоянного освещения монохроматическим светом структуры со стороны сульфида галлия. На рис. 5 представлены спектры фототока гетероструктуры при температурах 100 и $295 \mathrm{~K}$. При $100 \mathrm{~K}$ участок спектра в области 2.4-2.9 eV является спектром отдельного кристалла $\mathrm{GaS}$ с шириной запрещенной зоны $2.53 \mathrm{eV}$, которая проявляется в виде горба на спектре при той же энергии. С дальнейшим увеличением энергии кванта фоточувствительность кристалла возрастает и

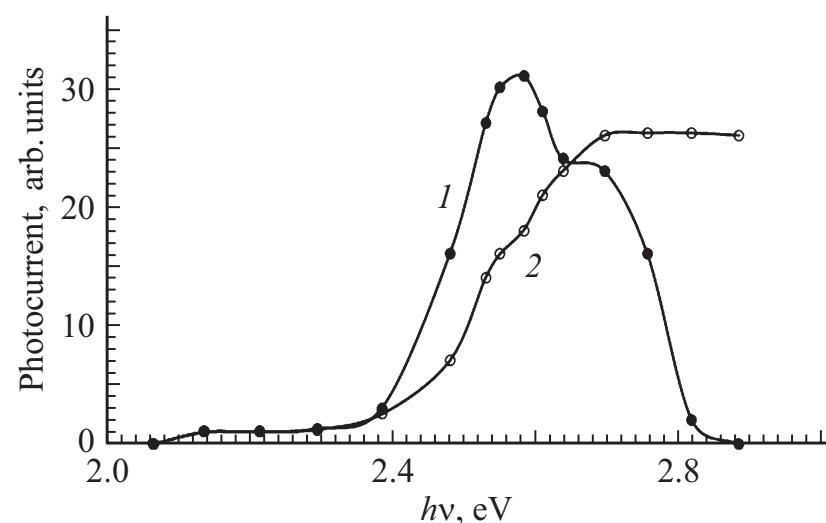

Рис. 5. Спектры фототока гетероструктуры $p-\mathrm{GaS}-n-\mathrm{InSe}$ при освещении со стороны GaS при различных температурах: 1 $295 \mathrm{~K}, 2-100 \mathrm{~K}$.

выше $2.7 \mathrm{eV}$ остается постоянной. Такая зависимость объясняется наличием пяти подзон в зоне проводимости, в которых неравновесные электроны обладают разными временами жизни и почти полным отсутствием поверхностных рекомбинационных центров в $\mathrm{GaS}$.

При $295 \mathrm{~K}$ в области выше $2.53 \mathrm{eV}$ происходит гашение фототока. Предполагаем, что оно обусловлено тепловым опустошением мелких уровней прилипания в $\mathrm{GaS}$. Наличие в $\mathrm{GaS}$ мелких уровней прилипания обнаружено в работе $[11,12]$. На спектре фототока проявляется примесная фотопроводимость в области $2.1-2.4 \mathrm{eV}$, т.е. у края собственной фотопроводимости, которая усиливается с увеличением температуры. Отсутствие вкладов неравновесных носителей, генерированных оптическим поглощением в тонкой пленке селенида индия, на фототок обусловлено наличием потенциаль- 


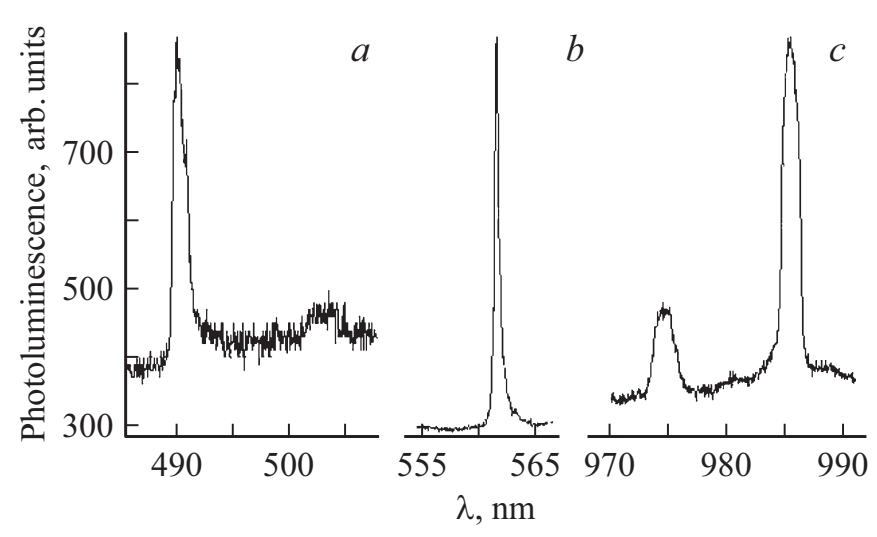

Рис. 6. Спектры люминесценции гетероперехода $p-\mathrm{GaS} / n-\mathrm{InSe}$ под действием лазерного излучения.

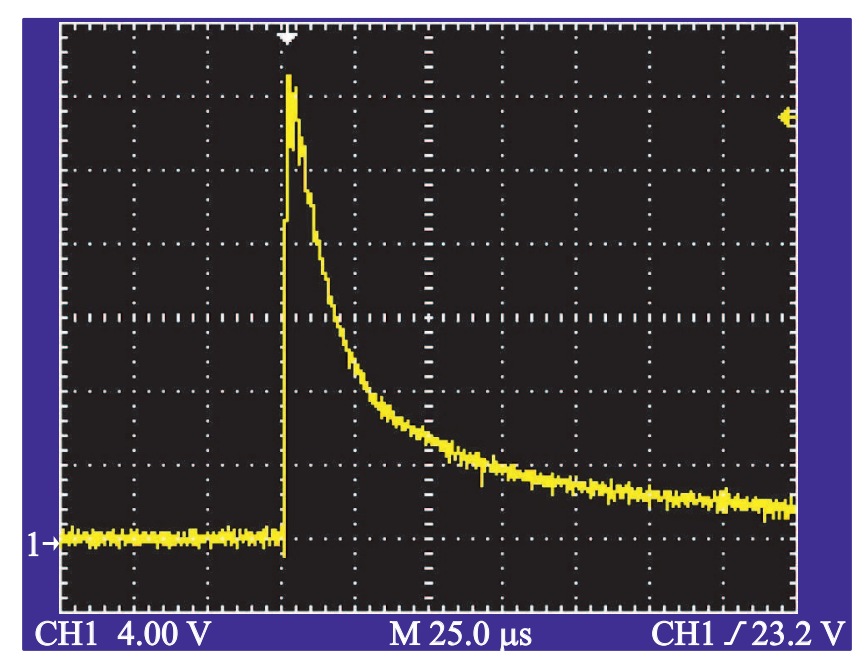

Рис. 7. Кривая релаксации фототока в гетеропереходе p$\mathrm{GaS} / n$-InSe под действием лазерного излучения.

ных барьеров для электронов и дырок на границе гетероперехода $p$-GaS $/ n$-InSe и их высокоскоростными рекомбинациями в области объемного заряда.

На рис. 6 представлены спектры фотолюминесценции гетероперехода $p$-GaS $/ n$-InSe под действием 3-й гармоники $\mathrm{Nd}$ : YAG-лазера $(\eta \omega=3.70 \mathrm{eV})$. Возбуждение осуществлялось со стороны $\mathrm{GaS}$ (широкозонное окно). Наблюдаемые линии излучения условно можно разделить на две части. Коротковолновые линии излучения с максимумами $\lambda_{1}=490 \mathrm{~nm}$ (с полушириной $\sim 10 \AA$ ) и $\lambda_{2}=561 \mathrm{~nm}$ относятся к излучениям, связанным с $\mathrm{GaS}$ (рис. 6, $a$ и $b$ ), а длинноволновые линии излучения $\lambda_{3}=975 \mathrm{~nm}$ и $\lambda_{4}=986 \mathrm{~nm}$ относятся к тонкой пленке InSe (рис. $6, c$ ).

По нашему мнению, коротковолновая линия излучения соответствует оптическому переходу в области края полосы поглощения $\mathrm{GaS}$, поскольку ширина запрещенной зоны $\mathrm{GaS}$ равна $2.5 \mathrm{eV}$ [6]. Излучение с максимумом $\lambda_{2}$ может быть обусловлено акцепторным уровнем, расположенным в запрещенной зоне $\mathrm{GaS}$ с энергией активации $E_{a}=0.37 \mathrm{eV}$, или вакансией $\mathrm{Ga}[13]$. Что касается длинноволновой линии излучения, относящейся к InSe, это довольно известная линия, связанная с оптическим переходом зона-зона $(\hbar v=1.27 \mathrm{eV})$ и аннигиляцией свободных экситонов $(\hbar \omega=1.25 \mathrm{eV})$ с энергией связи $20 \mathrm{meV}[14]$.

На рис. 7 представлена кривая релаксации фототока в гетеропереходе $p$-GaS $/ n-\mathrm{InSe}$. Исследование кривых релаксации неравновесной фотопроводимости под действием лазерного излучения также подтверждает наличие двух каналов рекомбинации в $\mathrm{GaS}$, собственного и примесного. Релаксация фототока происходит через быстрый и медленный каналы рекомбинации. Время $\tau$ быстрой релаксации, составляющее $\sim 15 \mu \mathrm{s}$, связано с собственным переходом, а время медленной - обусловлено примесным возбуждением и составляет $\tau \sim 200 \mu \mathrm{s}$.

\section{Заключение}

Методом химического осаждения из раствора получены тонкие пленки $\mathrm{GaS}$, толщина пленок составляла $0.2 \mu \mathrm{m}$. SEM-изображение тонкой пленки GaS показывает, что частицы неоднородно распределены на поверхности. Исследование XRD показывает, что тонкие пленки $\mathrm{GaS}$ имеют гексагональную кристаллическую структуру. Из спектра поглощения определена ширина запрещенной зоны $\mathrm{GaS}$, которая оказалось равной $E_{g}=2.53 \mathrm{eV}$. Термическим испарением InSe на поверхность кристалла $\mathrm{GaS}$ создан гетеропереход $p$-GaS $/ n$-InSe. Показано, что после лазерной обработки происходит увеличение фоточувствительности гетероструктуры $p$-GaS $/ n$-InSe на два порядка. Установлено, что обнаруженная в гетеропереходах $p$ - $\mathrm{GaS} / n$-InSe линия излучения с максимумом $490 \mathrm{~nm}$, с полушириной $\sim 10 \AA$ может явиться эффективным источником света, излучающим в ближней голубой области спектра. Быстрые фототоки $(\tau \sim 15 \mu \mathrm{s})$, наблюдаемые в кривых релаксации неравновесной фотопроводимости $p$-GaS $/ n$-InSe, позволяют утверждать, что на их основе можно создать детекторы лазерного излучения, работающие при комнатной температуре.

\section{Список литературы}

[1] Masanori Ohyama, Hiroshi Ito, Manabu Takeuchi. // Jap. J. Appl. Phys. 2005. V. 44(7A), P. 4780-4783. doi 10.1143/JJAP.44.4780

[2] Finkman E.,.Rizzo A. //Sol. St. Commun. 1974. V. 5. N 11-12. P. $1841-1845$.

[3] Kipperman A.H.M., van der Leeden G.A. // Sol. St. Commun. 1968. V. 6. N 9. P. 657-662.

[4] Wei An, Feng Wu, Hong Jiang, Guang-Shan Tian, XinZheng Li. // J. Chem. Phys. 2014. V. 141. P. 084701.

[5] Tomoyoshi Aono, Kunio Kase, Akira Kinoshita. //J. Appl. Phys. 1993. V. 74. P. 2818.

[6] Hoa C.H., Lin S.L. // J. Appl. Phys. 2006. V. 00. N 8. P. 83508.

[7] Уханов Ю.И. Оптические свойства полупроводников. М.: Наука, 1977. 306 с. 
[8] Давыдов А.С., Лубченко А.Ф. // ДАН СССР. 1968. Т. 179. № 6. C. $1301-1303$.

[9] Гарибов А.А., Мадатов Р.С., Комаров Ф.Ф., Пилько В.В., Мустафаев Ю.М., Ахмедов Ф.И., Джсахангиров М.М. //ФТП. 2015. Т. 49. В. 5. С. 599-602.

[10] Кязымзаде А.Г., Салманов В.М., Гусейнов А.Г., Мамедов Р.М., Салманова А.А., Ахмедова Ф.Ш. // Изв. вузов. 2017. T. 60. № 10. C. 30-33.

[11] Delice S., Bulur E., Gasanly N.M. // J. Phil. Mag. 2015. V. 95. P. 998-1006.

[12] Guler A., Isik M., Ahmedova F., Guseinov A., Gasanly N. // J. Luminesc. 2018. 33 (4). P. 759-763. doi 10.1002/bio.3473

[13] Tomoyoshi Aono, Kunio Kase, Akira Kinoshita. // J. Appl. Phys. 1993. V. 74. P. 2818.

[14] Hoa C.H., Lin S.L. // J. Appl. Phys. 2006. V. 100. P. 083508. 